\title{
Field dependent reduced ion mobilities of positive and negative ions in air and nitrogen in High Kinetic Energy lon Mobility Spectrometry (HiKE-IMS)
}

\author{
Maria Allers*1, Ansgar T. Kirk ${ }^{1}$, Christoph Schaefer ${ }^{1}$, Duygu Erdogdu², Walter Wissdorf ${ }^{2}$, Thorsten Benter ${ }^{2}$, Stefan \\ Zimmermann ${ }^{1}$ \\ ${ }^{1}$ Leibniz University Hannover, Institute of Electrical Engineering and Measurement Technology, Appelstraße 9a, \\ 30167 Hannover, Germany \\ 2 Department of Physical and Theoretical Chemistry, University of Wuppertal, Gauss Str. 20, 42119 Wuppertal, \\ Germany \\ *Corresponding author: allers@geml.uni-hannover.de
}

Keywords: HiKE-IMS, reduced ion mobility, reduced electric field strength, effective ion temperature

\section{Abstract}

In High Kinetic Energy Ion Mobility Spectrometry (HiKE-IMS), ions are formed in a reaction region and separated in a drift region, which is similar to classical drift tube ion mobility spectrometers (IMS) operated at ambient pressure. However, in contrast to the latter, the HiKE-IMS is operated at decreased background pressure of $10-40 \mathrm{mbar}$ and achieves high reduced electric field strengths of up to $120 \mathrm{Td}$ in both the reaction and the drift region. Thus, the HiKE-IMS allows insights into the chemical kinetics of ion bound water cluster systems at effective ion temperatures exceeding $1000 \mathrm{~K}$, although it is operated at the low absolute temperature of $45^{\circ} \mathrm{C}$. In this work, a HiKE-IMS with high resolving power of $R_{P}=140$ is used to study the dependence of reduced ion mobilities on the drift gas humidity and the effective ion temperature for the positive reactant ions $\mathrm{H}_{3} \mathrm{O}^{+}\left(\mathrm{H}_{2} \mathrm{O}\right)_{n}, \mathrm{O}_{2}{ }^{+}\left(\mathrm{H}_{2} \mathrm{O}\right)_{n}$, $\mathrm{NO}^{+}\left(\mathrm{H}_{2} \mathrm{O}\right)_{n}, \mathrm{NO}_{2}{ }^{+}\left(\mathrm{H}_{2} \mathrm{O}\right)_{n}$, and $\mathrm{NH}_{4}^{+}\left(\mathrm{H}_{2} \mathrm{O}\right)_{n}$, as well as the negative reactant ions $\mathrm{O}_{2}^{-}\left(\mathrm{H}_{2} \mathrm{O}\right)_{n}, \mathrm{O}_{3}^{-}\left(\mathrm{H}_{2} \mathrm{O}\right)_{n}, \mathrm{CO}_{3}^{-}$ $\left(\mathrm{H}_{2} \mathrm{O}\right)_{n}, \mathrm{HCO}_{3}^{-}\left(\mathrm{H}_{2} \mathrm{O}\right)_{n}$, and $\mathrm{NO}_{2}^{-}\left(\mathrm{H}_{2} \mathrm{O}\right)_{n}$. By varying the reduced electric field strength in the drift region, cluster transitions are observed in the ion mobility spectra. This is demonstrated for the cluster systems $\mathrm{H}_{3} \mathrm{O}^{+}\left(\mathrm{H}_{2} \mathrm{O}\right)_{n}$ and $\mathrm{NO}^{+}\left(\mathrm{H}_{2} \mathrm{O}\right)_{n}$.

\section{Introduction}

Ion mobility spectrometers (IMS) separate ions in an electric field on the basis of their ion mobility in a drift gas. In drift tube IMS, the ion mobility is determined by injecting small packets of ions into a drift tube where a constant electric field $E$ is prevailing. The drift time $t_{d}$ required by the ions to traverse the tube ${ }^{1-3}$ is measured and the ion mobility $K$, related to the drift velocity $v_{d}$ of the ions and thus to the ion's drift time, is calculated with equation 1.

$$
K=\frac{v_{d}}{E}=\frac{L}{t_{d} \cdot E}
$$

Here, $L$ is the length of the drift tube. To correct the influence of a changing number density due to pressure or temperature variations, a reduced ion mobility $K_{0}$ is calculated by scaling the neutral number density $N$ to the neutral number density at standard conditions $N_{0}$.

$$
K_{0}=K \cdot \frac{N}{N_{0}}
$$

According to comprehensive theoretical studies ${ }^{4,5}$, the reduced ion mobility $K_{0}$ depends on the mass $m$ of the ions, the mass $M$ of the neutral molecules and the ion-neutral collision cross section $\Omega$, as shown in equation (3). 


$$
K_{0}=\frac{3 \sqrt{2 \pi}}{16} \frac{z \mathrm{e}}{N_{0}} \sqrt{\frac{1}{\mathrm{k}_{\mathrm{b}} T_{\text {eff }}}\left[\frac{1}{m\left(T_{\text {eff }}\right)}+\frac{1}{M}\right]} \frac{1}{\Omega\left(T_{\text {eff }}\right)}
$$

Here, $z$ is the charge state of the ion, $e$ is the elementary charge, $k_{b}$ is the Boltzmann constant and $T_{\text {eff }}$ is the effective ion temperature. The latter is a measure of the average ion-molecule collision energy. As the motion of ions in a neutral gas is often accompanied by complex ion molecule reactions, the effective ion temperature has a profound effect on the reduced ion mobilities observed in IMS. In particular, the formation of ion bound water clusters according to reaction (4) affects the effective ion temperature having a major influence on the reduced ion mobility ${ }^{6,7}$.

$$
A^{+}\left(\mathrm{H}_{2} \mathrm{O}\right)_{n}+\mathrm{H}_{2} \mathrm{O}+\mathrm{M} \rightleftharpoons A^{+}\left(\mathrm{H}_{2} \mathrm{O}\right)_{n+1}+M
$$

Inside the drift tube, ion species undergo various hydration and dehydration reactions. At ambient pressure, the cluster reaction systems very quickly reach chemical equilibrium. In this equilibrium state, adjacent hydrated ion species $A^{+}\left(\mathrm{H}_{2} \mathrm{O}\right)_{n}$ and $A^{+}\left(\mathrm{H}_{2} \mathrm{O}\right)_{n+1}$ continuously interconvert to each other and finally coalesce into a single mobility peak. The effective ion temperature $T_{\text {eff }}$ determines the equilibrium cluster distribution and thus influences both, the average mass $m$ of the clustered ion as well as the average collision cross section $\Omega$.

According to the Wannier equation (5) ${ }^{8,5}$, the effective temperature $T_{\text {eff }}$ depends on the absolute temperature $T$ and the reduced electric field strength $E / N$, which is the ratio of electric field strength $E$ to neutral molecule density $N$, usually given in Townsend $\left(1 \mathrm{Td}=1 \cdot 10^{-21} \mathrm{Vm}^{2}\right)$.

$$
T_{\text {eff }}=T+\frac{M}{3 \mathrm{k}_{\mathrm{b}}}\left[K_{0}\left(T_{\text {eff }}\right) N_{0} \frac{E}{N}\right]^{2}
$$

It is worth noting that the effective ion temperature $T_{\text {eff }}$ can be assumed to be equivalent to the absolute temperature $T$ at low field conditions $\left(E / N<2 \mathrm{Td}\right.$ at $\left.298 \mathrm{~K}{ }^{9}\right)$ whereas the reduced electric field strength controls the effective ion temperature at higher fields.

Eiceman et al. studied the dependence of the reduced ion mobility of $\mathrm{H}_{3} \mathrm{O}^{+}\left(\mathrm{H}_{2} \mathrm{O}\right)_{n}, \mathrm{NO}^{+}\left(\mathrm{H}_{2} \mathrm{O}\right)_{n}$, and $\mathrm{NH}_{4}{ }^{+}\left(\mathrm{H}_{2} \mathrm{O}\right)_{n}$ on the effective ion temperature by varying the absolute temperature between $314 \mathrm{~K}$ and $523 \mathrm{~K}$ at low reduced electric field strengths between $0.37 \mathrm{Td}$ and $1.86 \mathrm{Td}^{10}$. A similar approach was adopted by Tabrizchi et al., Fernandez-Maestre et al., and Borsdorf et al. evaluating the influence of the effective ion temperature on the reduced ion mobility of several other positive and negative ions ${ }^{11-14}$. Varying the effective ion temperature between room temperature and a maximum of $523 \mathrm{~K}$, all groups found the reduced ion mobility to increase with increasing effective ion temperature due to the dissociation of water clusters. When IMS are operated at low electric field strengths, it is difficult to reach effective ion temperatures above $523 \mathrm{~K}$, as this requires a high temperature resistance of the materials. Nonetheless, as shown in this work, it is possible to extend these studies to higher effective ion temperatures by applying high reduced electric field strengths.

Additionally to the effective ion temperature, the drift gas humidity significantly affects the observed ion mobilities in IMS by changing the equilibrium cluster distribution. Several research groups have studied this effect using IMS operating under low field conditions. Borsdorf et al. analyzed the influence of the drift gas humidity on the peak positions of $\mathrm{O}_{2}{ }^{-}\left(\mathrm{H}_{2} \mathrm{O}\right)_{n}$ and some hydrated halogen anions ${ }^{6}$. Similar studies are performed by Zhang et al. and Mäkinen et al. considering $\mathrm{H}_{3} \mathrm{O}^{+}\left(\mathrm{H}_{2} \mathrm{O}\right)_{n}$ and $\mathrm{O}_{2}^{-}\left(\mathrm{H}_{2} \mathrm{O}\right)_{n}{ }^{15}$ as well as the protonated monomer and the proton-bound dimer ion of amines ${ }^{16}$. More recently, Izadi et al. systematically investigated the effect of temperature and drift gas humidity on the $\mathrm{NH}_{4}{ }^{+}\left(\mathrm{H}_{2} \mathrm{O}\right)_{n}$ and $\mathrm{H}_{3} \mathrm{O}^{+}\left(\mathrm{H}_{2} \mathrm{O}\right)_{n}$ cluster systems ${ }^{17}$. In all studies, it was found that the observed reduced ion mobilities decrease with increasing drift gas humidity due to enhanced cluster formation reactions. 
In this work, a High Kinetic Energy Ion Mobility Spectrometer (HiKE-IMS) ${ }^{18-20}$ is used to study the dependence of reduced ion mobilities on the drift gas humidity and the effective ion temperature for several hydrated ion species in air and nitrogen. Similar to classical drift tube IMS which are operated at ambient pressure, ions are produced in a reaction region before they are separated in the drift region of the HiKE-IMS. Unlike classical IMS, the HiKE-IMS is operated at decreased background gas pressures to reach high reduced electric field strengths of up to $120 \mathrm{Td}$ in both the reaction region and the drift region. Due to the operation at reduced background gas pressure and high reduced electric field strengths, the HiKE-IMS allows insights into the chemical kinetics of ion bound water cluster systems at effective ion temperatures exceeding $1000 \mathrm{~K}$. In particular, the high mobility resolving power of $R_{P}=140$ enables direct observation of cluster transitions in the ion mobility spectrum when varying the reduced electric field strength in the drift region.

In a number of applications, a profound knowledge of the reduced ion mobilities of hydrated ions $\mathrm{A}^{+}\left(\mathrm{H}_{2} \mathrm{O}\right)_{n}$ as a function of the water concentration and the reduced electric field strength is essential. For example, differential mobility spectrometers (DMS) separate ions based on the difference between their ion mobilities at low and high reduced electric field strength ${ }^{21}$. Furthermore, using proton transfer reaction mass spectrometers (PTR-MS) or selected ion flow drift tube mass spectrometers (SIFDT-MS) for trace gas analysis, the ion mobility of the reactant ions determines the ion-molecule reaction time required to calculate the analyte concentration in the sample gas ${ }^{22-24}$.

In the following, the dependence of the reduced ion mobilities of the positive reactant ions $\mathrm{H}_{3} \mathrm{O}^{+}\left(\mathrm{H}_{2} \mathrm{O}\right)_{n}$, $\mathrm{O}_{2}^{+}\left(\mathrm{H}_{2} \mathrm{O}\right)_{n}, \mathrm{NO}^{+}\left(\mathrm{H}_{2} \mathrm{O}\right)_{n}, \mathrm{NO}_{2}{ }^{+}\left(\mathrm{H}_{2} \mathrm{O}\right)_{n}$, and $\mathrm{NH}_{4}^{+}\left(\mathrm{H}_{2} \mathrm{O}\right)_{n}$, as well as the negative reactant ions $\mathrm{O}_{2}^{-}\left(\mathrm{H}_{2} \mathrm{O}\right)_{n}, \mathrm{O}_{3}{ }^{-}$ $\left(\mathrm{H}_{2} \mathrm{O}\right)_{n}, \mathrm{CO}_{3}^{-}\left(\mathrm{H}_{2} \mathrm{O}\right)_{n}, \mathrm{HCO}_{3}^{-}\left(\mathrm{H}_{2} \mathrm{O}\right)_{n}$, and $\mathrm{NO}_{2}^{-}\left(\mathrm{H}_{2} \mathrm{O}\right)_{n}$ on the drift gas humidity and the effective ion temperature are analyzed.

\section{Experimental setup}

\section{$\underline{\text { HiKE-IMS }}$}

A detailed description of the HiKE-IMS setup is given in the previous studies 2025,26 . The operating parameters used in this work are stated in Table 1. In contrast to the other studies, the sample gas flow is set to zero in this work and the drift gas flow is set to $38 \mathrm{ml} / \mathrm{min}$ (standard milliliter per minute, mass flow at reference conditions $20^{\circ} \mathrm{C}$ and $1013.25 \mathrm{hPa}$ ). The HiKE-IMS resolving power varies from $R=140$ at high reduced field conditions $(120 \mathrm{Td})$ to $R=80$ at lower reduced field conditions $(25 \mathrm{Td})$ in the drift region.

For the identification of single ion species related to signals in the ion mobility spectrum, the HiKE-IMSMS coupling introduced in a previous work ${ }^{27}$ is used.

Table 1: HiKE-IMS operating parameters.

${ }^{a} \mathrm{~m} / \mathrm{s} / \mathrm{min}$ : standard milliliter per minute, mass flow at reference conditions $20^{\circ} \mathrm{C}$ and $1013.25 \mathrm{hPa}$

\begin{tabular}{l|l}
\hline Parameter & Value \\
\hline Temperature & $45^{\circ} \mathrm{C}$ \\
Pressure & $14.3 \mathrm{mbar}$ \\
Drift gas flow & $38 \mathrm{ml}_{\mathrm{s}} / \mathrm{min}^{\mathrm{a}}$ \\
Drift gas humidity & $70 \mathrm{ppm}_{\mathrm{v}}-3600 \mathrm{ppm}_{\mathrm{v}}$ \\
Sample gas flow & $0 \mathrm{ml}_{\mathrm{s}} / \mathrm{min}^{\mathrm{a}}$ \\
Drift region length & $307.6 \mathrm{~mm}$
\end{tabular}




\begin{tabular}{l|l} 
Reduced drift field & $\begin{array}{l}20-115 \mathrm{Td} \text { (pos.) } \\
20-80 \mathrm{Td} \text { (neg.) }\end{array}$ \\
Reaction region length & $\begin{array}{l}77 \mathrm{~mm} \\
15-115 \mathrm{Td} \text { (pos.) } \\
15-100 \mathrm{Td} \text { (neg.) }\end{array}$ \\
Reduced reaction field & $1 \mu \mathrm{s}$
\end{tabular}

\section{Gas supply}

Two drift gas sources are available to study the reduced ion mobilities in air and nitrogen. These drift gas sources have been described in detail in a previous study ${ }^{27}$. In summary, purified air containing between $70 \mathrm{ppm}_{\mathrm{v}}$ and $3600 \mathrm{ppm}_{\mathrm{v}}$ water as well as $30 \mathrm{ppm}_{\mathrm{v}}$ carbon dioxide is available. Furthermore, purified nitrogen containing several tens of ppm $\mathrm{v}_{\mathrm{v}}$ oxygen and also between $70 \mathrm{ppm}_{\mathrm{v}}$ and $3600 \mathrm{ppm}_{\mathrm{v}}$ water as well as $30 \mathrm{ppm}_{\mathrm{v}}$ carbon dioxide can be used.

\section{Accuracy of the reported ion mobilities}

In this work, the experimental setup described above is used to measure reduced ion mobilities in dependence on the effective ion temperature and drift gas humidity. In the following, the experimental error is estimated.

The total error regarding the reduced ion mobility depends on the accuracies of the drift length $L$, the operating pressure $p$, the drift time $t_{\mathrm{d}}$, the drift voltage $U_{\mathrm{d}}$, and the absolute temperature $T$ according to equation (6), which follows from equations (1) and (2).

$$
K_{0}=\frac{1}{k_{\mathrm{b}} \cdot N_{0}} \cdot \frac{L^{2} \cdot p}{t_{\mathrm{d}} \cdot U_{\mathrm{d}} \cdot T}
$$

Here, $k_{\mathrm{b}}$ is the Boltzmann constant and $N_{0}$ is the Loschmidt constant (neutral density at standard conditions: $2.69 \cdot 10^{25} \mathrm{~m}^{-3}$ ). According to comprehensive studies from Hauck et al. ${ }^{28-30}$, every variable is considered in detail to estimate the total accumulated error in HiKE-IMS.

1. Absolute temperature $T$ : To maintain a constant operating temperature of $45^{\circ} \mathrm{C}$, the HiKE-IMS is embedded in a temperature-controlled housing. Before entering the housing, the drift gas is at room temperature. Nonetheless, we assume that the drift gas reaches the temperature of the housing before entering the drift region of the HiKE-IMS due to the very low heat capacity of the gas and the low drift gas flow of $38 \mathrm{~mL} / \mathrm{min}$. The temperature inside the housing is measured using the average value of six 1-wire digital thermometers (Maxim Integrated, DS 18S20) being distributed in the housing. These 1-wire digital thermometers reach an accuracy of $0.5 \mathrm{~K}$. However, temperature gradients inside the housing and thus along the drift tube cause major errors. According to the data from the six thermometers, the temperature inside the housing deviates from the average temperature of $318 \mathrm{~K}$ by $\pm 2 \mathrm{~K}$. Thus, we estimate the relative error $s_{T}$ regarding the absolute temperature to be $0.6 \%$.

2. Operating pressure $p$ : The pressure within the HiKE-IMS is monitored with a capacitive pressure gauge (Pfeiffer Vacuum, CMR 362) with a relative error of $0.2 \%$. However, the pressure gauge is adapted to the HiKE-IMS via a $0.5 \mathrm{~m}$ PEEK capillary with $1 \mathrm{~mm}$ inner diameter. The length of $0.5 \mathrm{~mm}$ is chosen to avoid electrical breakdown between the IMS electrodes at high potentials and the pressure gauge at ground potential. Nonetheless, this setup leads to pressure fluctuations being low pass filtered and measured with a certain time delay. 
Unfortunately, the error resulting from this effect is difficult to account for. Thus, we estimate the relative error $s_{p}$ regarding the operating pressure to be $0.2 \%$.

3. Drift length L: The distance from the ion shutter to the aperture grid is the major part of the drift length. Additionally, ions have to drift through the ion shutter and the region between aperture grid and Faraday detector. Calculating the drift length from engineering drawings, these regions are included. Furthermore, the thermal expansion of the electrode material (1.4305 stainless steel, $16 \mathrm{ppm} / \mathrm{K}$ ) and the insulation material (PEEK - Polyether ether ketone, $47 \mathrm{ppm} / \mathrm{K}$ ) when operating the HiKE-IMS at $45{ }^{\circ} \mathrm{C}$ instead of $25{ }^{\circ} \mathrm{C}$ is taken into account resulting in a total nominal drift length of $307.6 \mathrm{~mm}$. However, due to manufacturing tolerances, different thermal expansion as calculated and field inhomogeneities, the actual drift length might differ from the calculated nominal length. While the manufacturing tolerance of $\pm 50 \mu \mathrm{m}$ results in a low relative error of $\frac{50 \mu \mathrm{m}}{307.6 \mathrm{~mm}}=0.01 \%$, the relative error caused by a deviation of the assumed thermal expansion is considered more significant. In accordance with results found by Crawford et al. ${ }^{28}$, we assume the relative error imposed by thermal expansion to be $0.05 \%$ due to thermal stresses caused by the different coefficients of thermal expansion as well as an inaccurate temperature measurements (see above). In contrast, we neglect the influence of field inhomogeneities on the drift length due to two reasons. First, the drift tube reaches a high field ideality ${ }^{31}$. Second, in contrast to the electric field in the widespread Bradbury-Nielson ion shutters ${ }^{32,20}$, the tristate ion shutter does not distort the drift field due to three parallel grids with constant potential at the grid to the drift region. Thus, the overall relative error $s_{L}$ regarding the drift length is estimated to be $0.06 \%$ in a worst-case scenario.

4. Drift time $t_{d}$ : Spectra are recorded at a sampling interval of $25 \mathrm{~ns}$. As this interval is considerably shorter than the temporal peak widths in HiKE-IMS, the peak maxima can be precisely measured. Additionally, in order to determine the correct drift times, the time delay between the start of data acquisition and ion injection is taken into account. This time delay has been measured by an oscilloscope (UNI-T UTD2042C) to be $120 \mathrm{~ns} \pm 1 \mathrm{~ns}$. Furthermore, applying the tristate ion shutter mechanism ${ }^{20}$, the initial ion packet width should be identical to the gate opening time. Thus, with a gate opening time of $1 \mu \mathrm{s}$, we consider the peak maxima to be injected into the drift region after the half-opening time of $500 \mathrm{~ns}$. As the ion's drift times in HiKE-IMS are between $250 \mu \mathrm{s}$ (drift field of $120 \mathrm{Td}$ ) and $2 \mathrm{~ms}$ (drift field of $20 \mathrm{Td}$ ), the overall relative error $s_{t d}$ regarding the drift time is negligible.

5. Drift voltage $U_{d}:$ The drift voltage of the HiKE-IMS is supplied by a commercially available high voltage power supply (FuG Elektronik GmbH, HCP-35-20000). According to the data sheet, the output voltage deviates less than $0.01 \%$ from the nominal value over 8 hours and the residual ripple is just $0.01 \%$. We assume that the truly applied drift voltage is equal to the output voltage as the voltage drop over cable is negligible. Thus, the relative error sud regarding the drift voltage is also negligible.

Assuming these errors to be uncorrelated, the overall combined relative error $s_{\text {total }}$ regarding the reduced ion mobility can be estimated by taking the square root of the sum of the individual error squares according to GUM (Guide to the Expression of Uncertainty in Measurement ${ }^{33}$ ).

$$
s_{\text {total }}=\sqrt{s_{T}^{2}+s_{p}^{2}+2 \cdot s_{L}^{2}+s_{t d}^{2}+s_{U d}^{2}}=0.64 \%
$$


The reduced ion mobility will be stated as a function of drift gas humidity and effective ion temperature. These quantities might also be faulty. A dew point sensor (Michell Instruments, Easidew Transmitter) measures the moisture content of the drift gas with an accuracy of $\pm 2{ }^{\circ} \mathrm{C}$. Thus, the relative error regarding the drift gas humidity is about $20 \%$. Based on equations (5) and (6), the effective ion temperature $T_{\text {eff }}$ can be calculated from the absolute temperature $T$, the drift length $L$ and the drift time $t_{d}$. Hence, the relative error regarding the effective ion temperature is determined by the relative error regarding the absolute temperature and can be estimated to be about $0.6 \%$.

\section{Transient effects in HiKE-IMS}

In previous studies, the formation of positive and negative reactant ions in HiKE-IMS has been investigated in detail ${ }^{25,27,26}$. By coupling the HiKE-IMS to a mass spectrometer, the occurring positive reactant ions in purified air have been identified as $\mathrm{H}_{3} \mathrm{O}^{+}\left(\mathrm{H}_{2} \mathrm{O}\right)_{n}, \mathrm{O}_{2}{ }^{+}\left(\mathrm{H}_{2} \mathrm{O}\right)_{n}, \mathrm{NO}^{+}\left(\mathrm{H}_{2} \mathrm{O}\right)_{n}, \mathrm{NO}_{2}{ }^{+}\left(\mathrm{H}_{2} \mathrm{O}\right)_{n}$, and $\mathrm{NH}_{4}{ }^{+}\left(\mathrm{H}_{2} \mathrm{O}\right)_{n}$. In the negative ion polarity mode, the negative reactant ions $\mathrm{O}_{2}^{-}\left(\mathrm{H}_{2} \mathrm{O}\right)_{n}, \mathrm{O}_{3}{ }^{-}\left(\mathrm{H}_{2} \mathrm{O}\right)_{n}, \mathrm{CO}_{3}{ }^{-}$ $\left(\mathrm{H}_{2} \mathrm{O}\right)_{n}, \mathrm{HCO}_{3}^{-}\left(\mathrm{H}_{2} \mathrm{O}\right)_{n}$, and $\mathrm{NO}_{2}{ }^{-}\left(\mathrm{H}_{2} \mathrm{O}\right)_{n}$ have been detected. In this work, the reduced ion mobilities of these ion bound water cluster systems are analyzed in HiKE-IMS.

As stated in the introduction, the motion of ions in a neutral gas is often accompanied by complex ionmolecule reactions. At ambient pressure, the reaction systems very quickly reach chemical equilibrium ${ }^{34}$. However, due to the operation at reduced pressure, ions might be detected in HiKE-IMS before the chemical equilibrium is established. In particular, cluster association or dissociation reactions as well as ion neutral reactions inside the drift region might influence the observed ion mobility spectrum. For demonstration, two example are discussed below.

In HiKE-IMS, the abundance of $\mathrm{O}_{2}{ }^{+}\left(\mathrm{H}_{2} \mathrm{O}\right)_{n}$ is highly dependent on the reduced electric field strength and the background water concentration. If the water concentration is too high or the reduced electric field strength too low, $\mathrm{O}_{2}{ }^{+}\left(\mathrm{H}_{2} \mathrm{O}\right)_{\mathrm{n}}$ is converted to $\mathrm{H}_{3} \mathrm{O}^{+}\left(\mathrm{H}_{2} \mathrm{O}\right)_{\mathrm{n}}{ }^{25}$. Under selected conditions, this conversion reaction is also observed in the HiKE-IMS spectrum. Figure 1 shows the recorded HiKE-IMS spectrum at a reduced electric reaction field strength of $110 \mathrm{Td}$ and a reduced electric drift field strength of $105 \mathrm{Td}$. The water concentration is $690 \mathrm{ppm}_{\mathrm{v}}$ in both, the reaction and drift region. In the spectrum, three major peaks are discernible: The first peak is associated to $\mathrm{NO}^{+}\left(\mathrm{H}_{2} \mathrm{O}\right)_{n}$ ions. $\mathrm{H}_{3} \mathrm{O}^{+}\left(\mathrm{H}_{2} \mathrm{O}\right)_{n}$ ions represent the second peak and $\mathrm{O}_{2}{ }^{+}\left(\mathrm{H}_{2} \mathrm{O}\right)_{\mathrm{n}}$ ions form the third peak. Transient ion neutral reactions inside the drift region are clearly visible in the spectrum, i.e., an elevated baseline between the $\mathrm{H}_{3} \mathrm{O}^{+}\left(\mathrm{H}_{2} \mathrm{O}\right)_{n}$ peak and the $\mathrm{O}_{2}^{+}\left(\mathrm{H}_{2} \mathrm{O}\right)_{n}$ peak, which is caused by the conversion of $\mathrm{O}_{2}^{+}\left(\mathrm{H}_{2} \mathrm{O}\right)_{n}$ to $\mathrm{H}_{3} \mathrm{O}^{+}\left(\mathrm{H}_{2} \mathrm{O}\right)_{n}$.

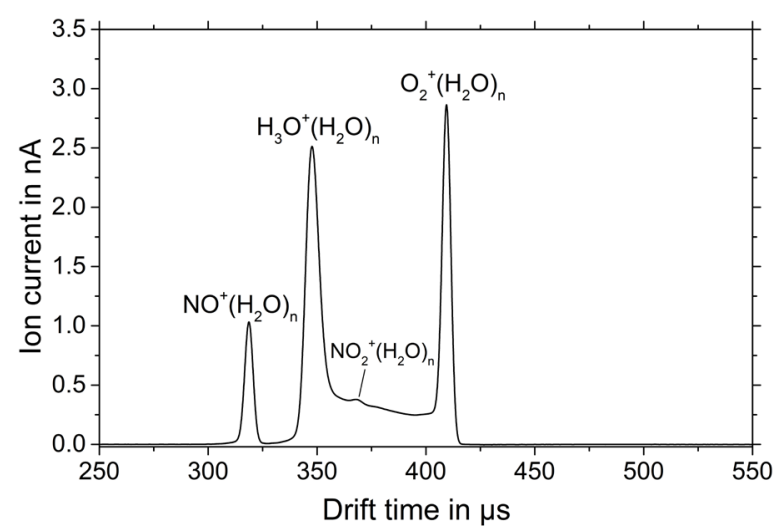

Figure 1: Recorded HiKE-IMS spectrum at a reduced electric reaction field strength of $110 \mathrm{Td}$ and a reduced electric drift field strength of $105 \mathrm{Td}$. The water concentration is $690 \mathrm{ppm}_{v}$ in both, the reaction and drift region. The pressure is $14.3 \mathrm{mbar}$, the temperature is $45{ }^{\circ} \mathrm{C}$. Due to the conversion of $\mathrm{O}_{2}^{+}\left(\mathrm{H}_{2} \mathrm{O}\right)_{n}$ to $\mathrm{H}_{3} \mathrm{O}^{+}\left(\mathrm{H}_{2} \mathrm{O}\right)_{n}$ while traversing the drift tube, the baseline between the $\mathrm{H}_{3} \mathrm{O}^{+}\left(\mathrm{H}_{2} \mathrm{O}\right)_{n}$ peak and the $\mathrm{O}_{2}^{+}\left(\mathrm{H}_{2} \mathrm{O}\right)_{n}$ peak is clearly elevated. 
In addition to ion neutral conversion reactions in the drift region, cluster association and dissociation reactions also considerably affect the ion mobility spectra observed in HiKE-IMS. To estimate the extent to which the dynamics of these reactions influence the ion mobility spectra in HiKE-IMS, Table 2 summarizes the rate coefficients $k_{\text {for }}$ for the three-body association reaction of a single water molecule to $\mathrm{H}_{3} \mathrm{O}^{+}, \mathrm{NO}^{+}, \mathrm{O}_{2}^{+}, \mathrm{O}_{2}^{-}, \mathrm{O}_{3}^{-}, \mathrm{NO}_{2}^{-}$, and $\mathrm{CO}_{3}^{-}$. Using these literature values, the reaction time $t_{\text {asso }}$ required to convert $95 \%$ of the bare ion species to the hydrated ion species is evaluated. Assuming the absence of an electric field, a pressure of $14.3 \mathrm{mbar}$ and a temperature of $298 \mathrm{~K}$, the reaction times $t_{\text {asso }}$ listed in Table 2 are calculated by equation (8).

$$
t_{\text {asso }}=-\frac{\ln (0.05)}{k_{\text {for }} \cdot c(M) \cdot c\left(H_{2} O\right)}
$$

Here is $c(M)$ the concentration of neutrals and $c\left(\mathrm{H}_{2} \mathrm{O}\right)$ the concentration of $\mathrm{H}_{2} \mathrm{O}$, both in the unit molecules $/ \mathrm{cm}^{3}$. As collisions with water molecules are required to initiate the association reaction, the reaction times $t_{\text {asso }}$ are highly dependent on the background water concentration. At a background water concentration of $70 \mathrm{ppm}_{\mathrm{v}}$, the reaction times $t_{\text {asso }}$ range between $104 \mu$ s (hydration of $\mathrm{H}_{3} \mathrm{O}^{+}$) and $3.5 \mathrm{~ms}$ (hydration of $\mathrm{CO}_{3}{ }^{-}$). Increasing the water concentration, the reaction times shorten. However, as the ion's drift times in HiKE-IMS are between $250 \mu$ s (drift field of $120 \mathrm{Td}$ ) and $2 \mathrm{~ms}$ (drift field of $20 \mathrm{Td}$ ), the dynamics of these cluster association reactions clearly affect the observed HiKE-IMS spectra, particularly at low background water concentrations.

Table 2: Rate coefficients of the three-body association reaction of a single water molecule to $\mathrm{H}_{3} \mathrm{O}^{+}, \mathrm{NO}^{+}, \mathrm{O}_{2}^{+}, \mathrm{O}_{2}^{-}, \mathrm{O}_{3}^{-}, \mathrm{NO}_{2}$, and $\mathrm{CO}_{3}-$ at $\mathrm{O} \mathrm{Td}$ as well as the calculated rate coefficients for the collision induced dissociation of the single hydrated ions at $115 \mathrm{Td}$. Furthermore, the calculated reaction time $t_{\text {asso }}$ required to convert $95 \%$ of the bare ion species to the hydrated ion species and the reaction time $t_{\text {diss }}$ to dissociate $95 \%$ of the hydrated ion species are given.

\begin{tabular}{|c|c|c|c|c|c|c|}
\hline & \multicolumn{4}{|c|}{ Forward reaction } & \multicolumn{2}{|c|}{ Reverse reaction } \\
\hline Reaction & $\begin{array}{l}\text { Rate } \\
\text { coefficient } \\
\text { at } 0 \mathrm{Td} \text { in } \\
10^{-28} \mathrm{~cm}^{6} / \mathrm{s}\end{array}$ & $\begin{array}{l}t_{\text {asso }} \\
(70 \\
\left.\text { ppm }_{v} \mathrm{H}_{2} \mathrm{O}\right)\end{array}$ & $\begin{array}{l}t_{\text {asso }} \\
(690 \\
\left.\text { ppm }_{v} \mathrm{H}_{2} \mathrm{O}\right)\end{array}$ & $\begin{array}{l}t_{\text {asso }} \\
(3600 \\
\left.\text { ppm }_{v} \mathrm{H}_{2} \mathrm{O}\right)\end{array}$ & $\begin{array}{l}\text { Rate } \\
\text { coefficient at } \\
115 \mathrm{Td} \text { in } \\
10^{-10} \mathrm{~cm}^{3} / \mathrm{s}\end{array}$ & $t_{\text {diss }}$ \\
\hline $\begin{array}{c}\mathrm{H}_{3} \mathrm{O}^{+}+\mathrm{H}_{2} \mathrm{O}+\mathrm{M} \rightleftharpoons \\
\mathrm{H}_{3} \mathrm{O}^{+}\left(\mathrm{H}_{2} \mathrm{O}\right)+\mathrm{M}\end{array}$ & $34^{35}$ & $104 \mu \mathrm{s}$ & $10 \mu \mathrm{s}$ & $2 \mu \mathrm{s}$ & 2.5 & $36 \mathrm{~ns}$ \\
\hline $\begin{array}{c}\mathrm{NO}^{+}+\mathrm{H}_{2} \mathrm{O}+\mathrm{M} \rightleftharpoons \\
\mathrm{NO}^{+}\left(\mathrm{H}_{2} \mathrm{O}\right)+\mathrm{M}\end{array}$ & $1.3^{36}$ & $2.7 \mathrm{~ms}$ & $277 \mu \mathrm{s}$ & $53 \mu \mathrm{s}$ & 4.0 & $23 \mathrm{~ns}$ \\
\hline $\begin{array}{c}\mathrm{O}_{2}{ }^{+}+\mathrm{H}_{2} \mathrm{O}+\mathrm{M} \rightleftharpoons \\
\mathrm{O}_{2}{ }^{+}\left(\mathrm{H}_{2} \mathrm{O}\right)+M\end{array}$ & $2.6^{37}$ & $1.4 \mathrm{~ms}$ & $138 \mu \mathrm{s}$ & $26 \mu \mathrm{s}$ & 5.2 & $175 \mathrm{~ns}$ \\
\hline $\begin{array}{c}\mathrm{O}_{2}^{-}+\mathrm{H}_{2} \mathrm{O}+\mathrm{M} \rightleftharpoons \\
\mathrm{O}_{2}^{-}\left(\mathrm{H}_{2} \mathrm{O}\right)+M\end{array}$ & $2.2^{38}$ & $1.6 \mathrm{~ms}$ & $163 \mu \mathrm{s}$ & $31 \mu \mathrm{s}$ & 1.3 & $68 \mathrm{~ns}$ \\
\hline $\begin{array}{c}\mathrm{O}_{3}^{-}+\mathrm{H}_{2} \mathrm{O}+\mathrm{M} \rightleftharpoons \\
\mathrm{O}_{3}^{-}\left(\mathrm{H}_{2} \mathrm{O}\right)+M\end{array}$ & $2.7^{38}$ & $1.3 \mathrm{~ms}$ & $133 \mu \mathrm{s}$ & $25 \mu \mathrm{s}$ & 4.4 & $21 \mathrm{~ns}$ \\
\hline $\begin{array}{c}\mathrm{NO}_{2}^{-}+\mathrm{H}_{2} \mathrm{O}+\mathrm{M} \rightleftharpoons \\
\mathrm{NO}_{2}{ }^{-}\left(\mathrm{H}_{2} \mathrm{O}\right)+M\end{array}$ & $1.6^{38}$ & $2.2 \mathrm{~ms}$ & $225 \mu \mathrm{s}$ & $43 \mu \mathrm{s}$ & 5.0 & $18 \mathrm{~ns}$ \\
\hline $\begin{array}{c}\mathrm{CO}_{3}^{-}+\mathrm{H}_{2} \mathrm{O}+\mathrm{M} \rightleftharpoons \\
\mathrm{CO}_{3}{ }^{-}\left(\mathrm{H}_{2} \mathrm{O}\right)+M\end{array}$ & $1^{38}$ & $3.5 \mathrm{~ms}$ & $360 \mu \mathrm{s}$ & $69 \mu \mathrm{s}$ & 9.7 & $9 \mathrm{~ns}$ \\
\hline
\end{tabular}

In Figure 2, this is illustrated based on the $\mathrm{NO}^{+}$bound water cluster system. Figure 2 (left) depicts the recorded HiKE-IMS spectra at a reduced electric drift field strength $E_{\mathrm{DR}} / N$ of $25 \mathrm{Td}$ and a background water concentration of $70 \mathrm{ppm}_{\mathrm{v}}$ for different reduced electric reaction field strengths $E_{\mathrm{RR}} / N$. At a reduced electric reaction field strength $E_{R R} / N$ of $15 \mathrm{Td}$, the $\mathrm{NO}^{+}\left(\mathrm{H}_{2} \mathrm{O}\right)_{n}$ ions form a single symmetric peak. However, increasing the reduced reaction field strength up to $50 \mathrm{Td}$, the peak deforms and a small second peak with a significantly lower drift time occurs in the spectrum. For field strengths 
exceeding $50 \mathrm{Td}$, no further change of the spectrum is observed. This effect is due to the dynamics of the cluster association process. In the thermodynamic equilibrium at a reduced electric field strength of $15 \mathrm{Td}$ and a background water concentration of $70 \mathrm{ppm}_{\mathrm{v}}$, the single hydrated $\mathrm{NO}^{+}\left(\mathrm{H}_{2} \mathrm{O}\right)$ is the dominating $\mathrm{NO}^{+}$species in the drift region ${ }^{25}$. At low reduced electric reaction field strength of $15 \mathrm{Td}$, mainly this hydrated ion species is injected into the drift region. Therefore, no further conversion reactions of the cluster in the drift region are required to reach the equilibrium and a single peak associated with the hydrated $\mathrm{NO}^{+}\left(\mathrm{H}_{2} \mathrm{O}\right)$ occurs in the HiKE-IMS spectrum. However, increasing the reduced electric reaction field strength from $15 \mathrm{Td}$ to $50 \mathrm{Td}$, the collision induced dissociation of the $\mathrm{NO}^{+}\left(\mathrm{H}_{2} \mathrm{O}\right)$ cluster inside the reaction region leads to increased amounts of bare $\mathrm{NO}^{+}$ions being injected into the drift region. A significant fraction of the bare $\mathrm{NO}^{+}$ions is hydrated in the drift region and results in the distortion of the $\mathrm{NO}^{+}\left(\mathrm{H}_{2} \mathrm{O}\right)$ peak. The remaining bare $\mathrm{NO}^{+}$ions are not hydrated and form another small peak.

In addition to the data of the cluster association reactions, Table 2 also contains data of the reverse cluster dissociation reaction at an exemplary reduced electric field strength of $115 \mathrm{Td}$. As described in detail in a previous work ${ }^{25}$, the rate coeffcients of the dissociation reactions at $115 \mathrm{Td}$ are estimated from the rate coefficients of the association reaction, its molar standard reaction enthalpy and its molar standard reaction entropy using van't Hoff equations. As the dissociation reactions are initiated by collisions with any neutral molecule, the reaction times $t_{\text {diss }}$ required to dissociate $95 \%$ of the hydrated ion species are only dependent on the total number density in the background gas. Furthermore, the dissociation reactions are bimolecular leading to much faster dissociation reactions than the cluster association reactions. The calculated reaction times $t_{\text {diss }}$ are significantly shorter ranging between $10 \mathrm{~ns}$ and $200 \mathrm{~ns}$. Thus, as shown in Figure 2 (right), the dynamics of collision induced cluster dissociation reactions in the drift region are not observed in the HiKE-IMS spectra. Figure 2 (right) depicts the recorded HiKE-IMS spectra at a reduced electric drift field strength of $115 \mathrm{Td}$ and a background water concentration of $70 \mathrm{ppm}_{\mathrm{v}}$ for different reduced electric field strengths in the reaction region. In this example, a single symmetrical peak associated with $\mathrm{NO}^{+}$occurs in the spectra independent on the reduced electric reaction field strength. In the thermodynamic equilibrium at a reduced electric field strength of $115 \mathrm{Td}$ and a background water concentration of $70 \mathrm{ppm}_{\mathrm{v}}$, the bare $\mathrm{NO}^{+}$is the dominating ion species in the drift region ${ }^{25}$. However, at a reduced electric reaction field strength of $15 \mathrm{Td}$, the hydrated species $\mathrm{NO}^{+}\left(\mathrm{H}_{2} \mathrm{O}\right)$ is injected in the drift region. Nonetheless, the chemical equilibrium of the $\mathrm{NO}^{+}$bound water cluster system inside drift region is quickly reached as the collision induced dissociation of the hydrated species $\mathrm{NO}^{+}\left(\mathrm{H}_{2} \mathrm{O}\right)$ occurs very quickly. Thus, an influence of the reduced electric reaction field strength on the shape of the peak is not visible.
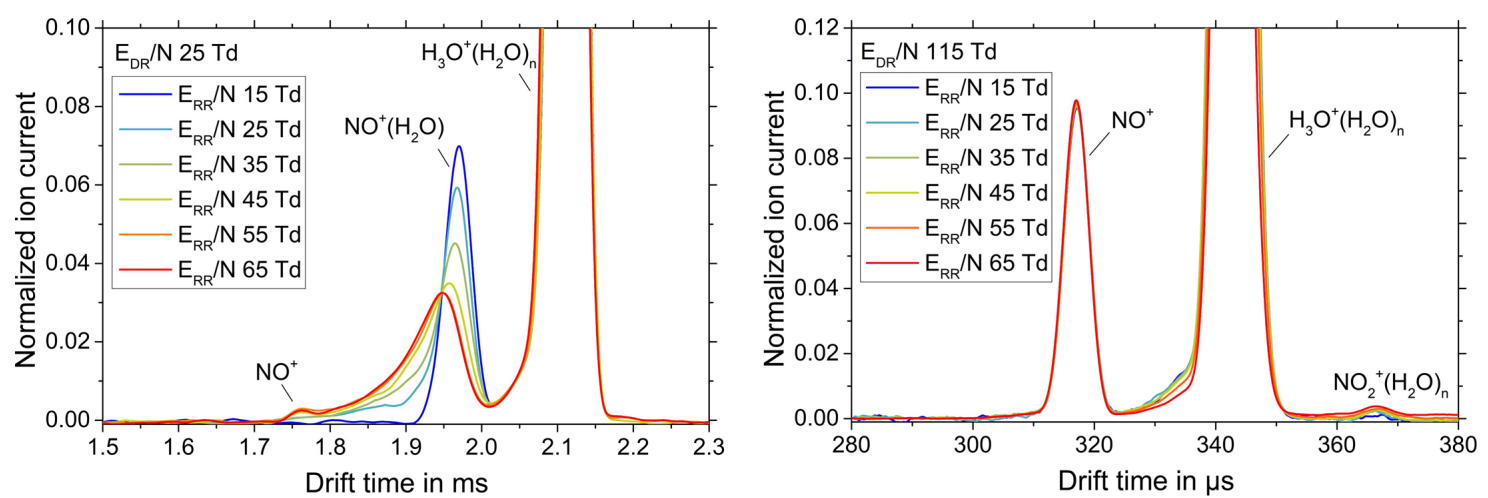

Figure 2: Recorded HiKE-IMS spectra at a background water concentration of 70 ppm $m_{v}$ for different reduced electric field strengths in the reaction region. Reduced electric drift field strength $25 \mathrm{Td}$ (left figure). Reduced electric drift field strength $115 \mathrm{Td}$ (right figure). The pressure is $14.3 \mathrm{mbar}$, the temperature is $45^{\circ} \mathrm{C}$. All spectra are normalized to the total charge in the spectrum. 
In summary, these results show that the dynamics of ion neutral reactions as well as cluster association reactions in the drift region might significantly affect the observed HiKE-IMS spectra of the hydrated ions studied in this work. Thus, when investigating the reduced ion mobilities of these ion bound water cluster systems in HiKE-IMS, these effects have to be taken into account. It is particularly important to choose a proper reduced electric reaction field strength for every individual ion bound water cluster system.

\section{Investigation of reduced ion mobilities in HiKE-IMS}

In this work, the reduced ion mobilities of the positive reactant ions $\mathrm{H}_{3} \mathrm{O}^{+}\left(\mathrm{H}_{2} \mathrm{O}\right)_{n}, \mathrm{O}_{2}^{+}\left(\mathrm{H}_{2} \mathrm{O}\right)_{n}, \mathrm{NO}^{+}\left(\mathrm{H}_{2} \mathrm{O}\right)_{n}$, $\mathrm{NO}_{2}{ }^{+}\left(\mathrm{H}_{2} \mathrm{O}\right)_{n}$, and $\mathrm{NH}_{4}^{+}\left(\mathrm{H}_{2} \mathrm{O}\right)_{n}$, as well as the negative reactant ions $\mathrm{O}_{2}^{-}\left(\mathrm{H}_{2} \mathrm{O}\right)_{n}, \mathrm{O}_{3}^{-}\left(\mathrm{H}_{2} \mathrm{O}\right)_{n}, \mathrm{CO}_{3}^{-}\left(\mathrm{H}_{2} \mathrm{O}\right)_{n}$, $\mathrm{HCO}_{3}^{-}\left(\mathrm{H}_{2} \mathrm{O}\right)_{n}$, and $\mathrm{NO}_{2}^{-}\left(\mathrm{H}_{2} \mathrm{O}\right)_{n}$ are analyzed in dependence on the effective ion temperature at three different drift gas humidities in purified air and nitrogen. The effective ion temperature is varied by sweeping the reduced electric drift field strength between $20 \mathrm{Td}$ and $115 \mathrm{Td}$ resulting in a change of the effective ion temperature according to the Wannier equation (equation (5)). Increasing the reduced electric drift field strength, successive dehydration of the ions occurs due to enhanced collision induced dissociation reactions. The underlying dissociation mechanism should be briefly discussed. The electric field accelerates the cluster ions. Upon colliding with neutral molecules, the kinetic energy of the ions is converted into internal energy. The cluster ions dissociate when their internal energy exceeds their dissociation energy. In Table 3, the dissociation energies of the ion bound water cluster systems analyzed in this work are stated.

Table 3: Dissociation energy in eV for several ion bound water cluster systems.

\begin{tabular}{|c|c|c|c|c|c|c|c|c|c|c|}
\hline & \multicolumn{10}{|c|}{$A^{+/-}\left(H_{2} O\right)_{n}+H_{2} O+M \rightleftharpoons A^{+/-}\left(H_{2} O\right)_{n+1}+M$} \\
\hline$n+1 \rightarrow n$ & $\mathrm{H}_{3} \mathrm{O}^{+}$ & $\mathrm{NH}_{4}^{+}$ & $\mathrm{NO}^{+}$ & $\mathrm{NO}_{2}^{+}$ & $\mathrm{O}_{2}^{+}$ & $\mathrm{O}_{2}^{-}$ & $\mathrm{O}_{3}^{-}$ & $\mathrm{CO}_{3}^{-}$ & $\mathrm{HCO}_{3}^{-}$ & $\mathrm{NO}_{2}^{-}$ \\
\hline $1 \rightarrow 0$ & $1.37^{39}$ & $0.75^{40}$ & $0.80^{41}$ & $0.78^{42}$ & $0.80^{43}$ & $0.80^{44}$ & & $0.61^{45}$ & $0.68^{45}$ & $0.62^{46}$ \\
\hline $2 \rightarrow 1$ & $0.84^{39}$ & $0.644^{40}$ & $0.70^{41}$ & $0.69^{42}$ & & $0.75^{44}$ & $0.51^{38}$ & $0.59^{45}$ & $0.65^{45}$ & $0.56^{46}$ \\
\hline $3 \rightarrow 2$ & $0.78^{39}$ & $0.58^{40}$ & $0.59^{41}$ & $0.61^{42}$ & & $0.67^{44}$ & $0.46^{38}$ & $0.57^{45}$ & $0.59^{45}$ & $0.45^{46}$ \\
\hline $4 \rightarrow 3$ & $0.55^{39}$ & $0.53^{40}$ & & & & & & & & \\
\hline
\end{tabular}

The highest energy is required to dissociate $\mathrm{H}_{3} \mathrm{O}^{+}\left(\mathrm{H}_{2} \mathrm{O}\right)(1.37 \mathrm{eV})$. In contrast, the dissociation energies of $\mathrm{NH}_{4}{ }^{+}\left(\mathrm{H}_{2} \mathrm{O}\right), \mathrm{NO}^{+}\left(\mathrm{H}_{2} \mathrm{O}\right), \mathrm{NO}_{2}{ }^{+}\left(\mathrm{H}_{2} \mathrm{O}\right), \mathrm{O}_{2}{ }^{+}\left(\mathrm{H}_{2} \mathrm{O}\right)$ and $\mathrm{O}_{2}^{-}\left(\mathrm{H}_{2} \mathrm{O}\right)$ range between just 0.75 and $0.8 \mathrm{eV}$, the dissociation energies of $\mathrm{O}_{3}^{-}\left(\mathrm{H}_{2} \mathrm{O}\right), \mathrm{CO}_{3}^{-}\left(\mathrm{H}_{2} \mathrm{O}\right), \mathrm{HCO}_{3}^{-}\left(\mathrm{H}_{2} \mathrm{O}\right)$ and $\mathrm{NO}_{2}^{-}\left(\mathrm{H}_{2} \mathrm{O}\right)$ are even lower. Dependent on the background water concentration and pressure, the cluster transition from $\mathrm{H}_{3} \mathrm{O}^{+}\left(\mathrm{H}_{2} \mathrm{O}\right)$ to $\mathrm{H}_{3} \mathrm{O}^{+}$ occurs at reduced electric field strengths between $90 \mathrm{Td}$ and $120 \mathrm{Td}{ }^{47,48}$. It is worth noting that the mean collision energy at $120 \mathrm{Td}$ is about $0.16 \mathrm{eV}^{22}$. Thus, the average single collision will not provide sufficient energy to dissociate $\mathrm{H}_{3} \mathrm{O}^{+}\left(\mathrm{H}_{2} \mathrm{O}\right)$. In contrast, the required dissociation energy is progressively deposited into the ion by a multitude of collisions ${ }^{22,49}$.

In the following, the measured reduced ion mobilities of $\mathrm{H}_{3} \mathrm{O}^{+}\left(\mathrm{H}_{2} \mathrm{O}\right)_{n}, \mathrm{NO}^{+}\left(\mathrm{H}_{2} \mathrm{O}\right)_{n}$ and $\mathrm{O}_{2}{ }^{+}\left(\mathrm{H}_{2} \mathrm{O}\right)_{n}$ in air and nitrogen are discussed in detail. The measured reduced ion mobilities of the other ion bound water cluster systems stated above are listed in the supporting information. 


\section{$\left.\underline{\mathrm{H}_{3} \mathrm{O}^{+}} \underline{\mathrm{H}}_{2} \underline{\mathrm{O}}\right)_{n}$}

To avoid ion neutral reactions in the drift region that may influence the observed ion mobilities of $\mathrm{H}_{3} \mathrm{O}^{+}\left(\mathrm{H}_{2} \mathrm{O}\right)_{n}$, the reduced electric reaction field strength is set to $15 \mathrm{Td}$ in all measurements. At this reaction field strength, mainly $\mathrm{H}_{3} \mathrm{O}^{+}\left(\mathrm{H}_{2} \mathrm{O}\right)_{n}$ ions and small amounts of $\mathrm{NO}^{+}\left(\mathrm{H}_{2} \mathrm{O}\right)_{n}$ ions are injected into the drift region ${ }^{25}$. Thus, the conversion reaction of $\mathrm{O}_{2}{ }^{+}\left(\mathrm{H}_{2} \mathrm{O}\right)_{n}$ to $\mathrm{H}_{3} \mathrm{O}^{+}\left(\mathrm{H}_{2} \mathrm{O}\right)_{n}$ inside the drift region does not affect the observed HiKE-IMS spectra.

Figure 3 depicts the ion mobility spectra of $\mathrm{H}_{3} \mathrm{O}^{+}\left(\mathrm{H}_{2} \mathrm{O}\right)_{n}$ in purified air recorded at different reduced electric drift field strengths between $70 \mathrm{Td}$ and $105 \mathrm{Td}$ and a drift gas humidity of $70 \mathrm{ppm}_{\mathrm{v}}$. To allow the comparison of ion mobility spectra for different reduced electric drift field strengths, the drift time $t_{d}$ is converted into the reduced ion mobility $K_{0}$ according to equation (6). In addition, the $K_{0}$-axis has a reciprocal scale to avoid peak distortion, as the reduced mobility $K_{0}$ is inversely proportional to the drift time $t_{d}$.

Increasing the reduced electric drift field strength, a general increase of the reduced ion mobility of $\mathrm{H}_{3} \mathrm{O}^{+}\left(\mathrm{H}_{2} \mathrm{O}\right)_{n}$ is observed. Furthermore, as shown in Figure 3a, particularly between $70 \mathrm{Td}$ and $105 \mathrm{Td}$, the peak of the $\mathrm{H}_{3} \mathrm{O}^{+}\left(\mathrm{H}_{2} \mathrm{O}\right)_{n}$ ions is distorted. From a tailing to higher reduced mobilities at $70 \mathrm{Td}$, the peak broadens at $80 \mathrm{Td}, 85 \mathrm{Td}$ and $90 \mathrm{Td}$, leading to a peak with significantly increased reduced mobility at $105 \mathrm{Td}$. As the distorted and broadened peaks do not contain any other ion species than $\mathrm{H}_{3} \mathrm{O}^{+}\left(\mathrm{H}_{2} \mathrm{O}\right)_{n}$ 27 , we expect the cluster transition from $\mathrm{H}_{3} \mathrm{O}^{+}\left(\mathrm{H}_{2} \mathrm{O}\right)$ to $\mathrm{H}_{3} \mathrm{O}^{+}$to cause this behavior. At elevated drift gas humidities, this effect is less pronounced. As shown in Figure 3b, at the elevated drift gas humidity of $690 \mathrm{ppm}_{\mathrm{v}}$, the cluster transition can only be recognized by a less distinctive broadening of the peak. Furthermore, the field strength required to initiate the cluster transition increases with increasing drift gas humidity.

a)

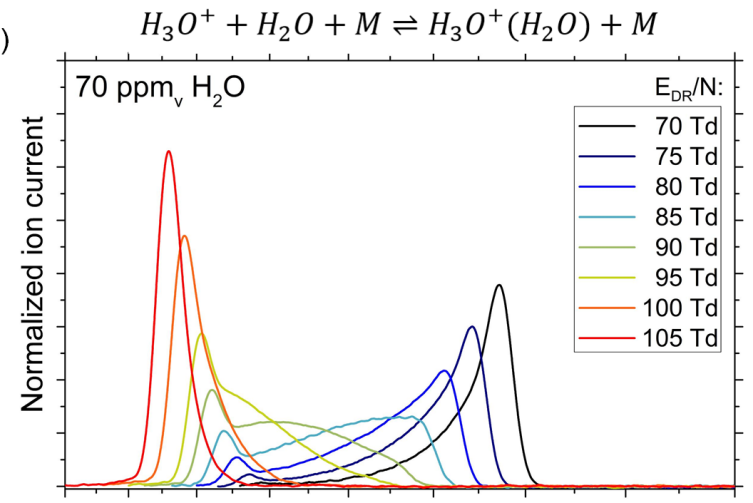

b)

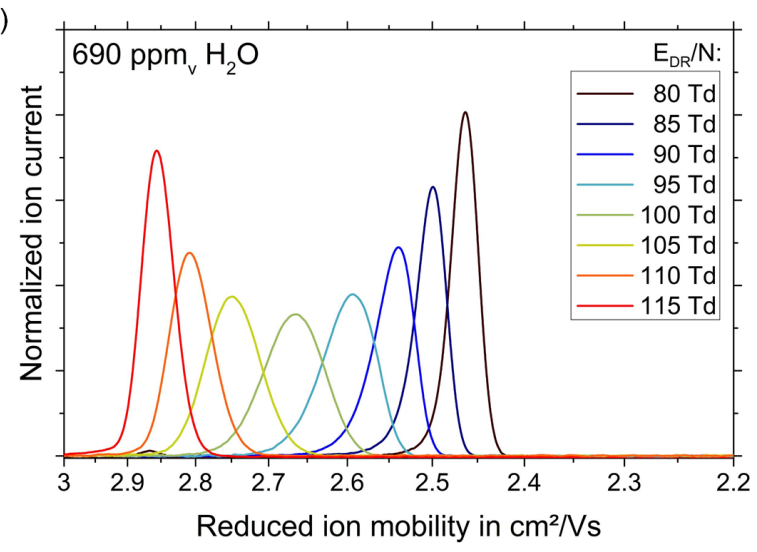

Figure 3: Recorded ion mobility spectra of $\mathrm{H}_{3} \mathrm{O}^{+}\left(\mathrm{H}_{2} \mathrm{O}\right)_{n}$ in purified air at different reduced electric drift field strengths, the reduced reaction field strength is constant at $15 \mathrm{Td}$. a) Drift gas humidity of 70 ppm. b) Drift gas humidity of 690 ppm. The pressure is $14.3 \mathrm{mbar}$, the temperature is $45^{\circ} \mathrm{C}$. All spectra are normalized to the total charge in the spectrum. 
In Figure 4 and in the supporting information, the measured reduced ion mobilities of $\mathrm{H}_{3} \mathrm{O}^{+}\left(\mathrm{H}_{2} \mathrm{O}\right)_{n}$ in purified air and nitrogen are summarized in dependence on the reduced electric drift field strength for three different drift gas humidities. The stated reduced ion mobility is the weighted average reduced ion mobility of the $\mathrm{H}_{3} \mathrm{O}^{+}\left(\mathrm{H}_{2} \mathrm{O}\right)_{n}$ peak. Comparing the results in air with those in nitrogen, it is apparent that the reduced ion mobilities in air are higher than in nitrogen. As known from other studies ${ }^{50,51}$, this effect can be explained considering the gas polarizabilities of nitrogen and oxygen. The gas polarizability correlates linearly to the ion neutral collision cross section ${ }^{4,52}$. As nitrogen exhibits a higher gas polarizability than oxygen, the mobilities in nitrogen are lower. This difference in mobility directly impacts the electric field strength required for the dissociation of the water clusters. In air, the reduced ion mobility of $\mathrm{H}_{3} \mathrm{O}^{+}\left(\mathrm{H}_{2} \mathrm{O}\right)_{n}$ increases at higher rate and thus the cluster size decreases at higher rate around $50 \mathrm{Td}$ and $90 \mathrm{Td}$, whereas in nitrogen, the reduced ion mobility of $\mathrm{H}_{3} \mathrm{O}^{+}\left(\mathrm{H}_{2} \mathrm{O}\right)_{n}$ increases at higher rate at elevated field strengths around $55 \mathrm{Td}$ and $95 \mathrm{Td}$. To initiate cluster dissociation, the effective ion temperature must exceed a certain value. Following the Wannier equation (5), the effective ion temperature $T_{\text {eff }}$ is dependent on the absolute temperature $T$, the reduced ion mobility $K_{0}$, the reduced electric field strength $E / N$ and the mass $M$ of the neutral gas molecules. Therefore, higher reduced electric field strengths are necessary in nitrogen to achieve the same effective ion temperature as in air.
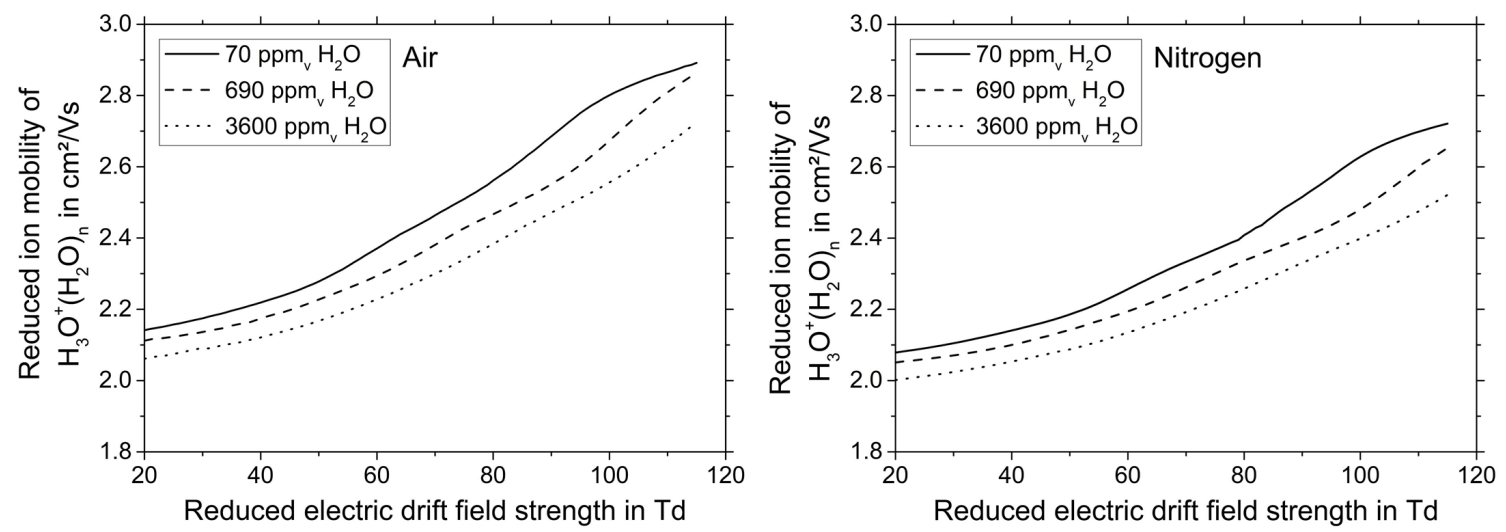

Figure 4: Recorded reduced ion mobilities of $\mathrm{H}_{3} \mathrm{O}^{+}\left(\mathrm{H}_{2} \mathrm{O}\right)_{n}$ in purified air (left) and nitrogen (right) in dependence on the reduced electric drift field strength for three different drift gas humidities. In all measurements, the reduced electric reaction field strength is $15 \mathrm{Td}$, the pressure is $14.3 \mathrm{mbar}$, and the temperature is $45^{\circ} \mathrm{C}$. The stated reduced ion mobility is the weighted average reduced ion mobility of the $\mathrm{H}_{3} \mathrm{O}^{+}\left(\mathrm{H}_{2} \mathrm{O}\right)_{n}$ peak.

\section{$\underline{\mathrm{NO}^{+}\left(\mathrm{H}_{2} \mathrm{O}\right)_{n}}$}

As explained above, to exclude the influence of cluster association reactions on the observed ion mobility spectra of $\mathrm{NO}^{+}\left(\mathrm{H}_{2} \mathrm{O}\right)_{n}$, a low reduced electric reaction field strength is required. Thus, in the following measurements, the reduced electric reaction field strength is kept constant at $15 \mathrm{Td}$.

The results for $\mathrm{NO}^{+}\left(\mathrm{H}_{2} \mathrm{O}\right)_{n}$ are similar to those for $\mathrm{H}_{3} \mathrm{O}^{+}\left(\mathrm{H}_{2} \mathrm{O}\right)_{n}$. Figure 5a depicts the ion mobility spectrum of $\mathrm{NO}^{+}\left(\mathrm{H}_{2} \mathrm{O}\right)_{\mathrm{n}}$ in purified air recorded at different reduced electric drift field strengths between $20 \mathrm{Td}$ and $60 \mathrm{Td}$ and a drift gas humidity of $70 \mathrm{ppm}_{\mathrm{v}}$. As observed for $\mathrm{H}_{3} \mathrm{O}^{+}\left(\mathrm{H}_{2} \mathrm{O}\right)_{n}$, the reduced ion mobility of $\mathrm{NO}^{+}\left(\mathrm{H}_{2} \mathrm{O}\right)_{n}$ increases with increasing reduced electric drift field strength. In particular, between $20 \mathrm{Td}$ and $60 \mathrm{Td}$, the peak of the $\mathrm{NO}^{+}\left(\mathrm{H}_{2} \mathrm{O}\right)_{n}$ ions is distorted due to the cluster transition from $\mathrm{NO}^{+}\left(\mathrm{H}_{2} \mathrm{O}\right)$ to $\mathrm{NO}^{+}$. Furthermore, as shown in Figure $5 \mathrm{~b}$, at elevated drift gas humidities, this effect is less pronounced and higher field strengths are required to initiate the cluster transition. 
a)

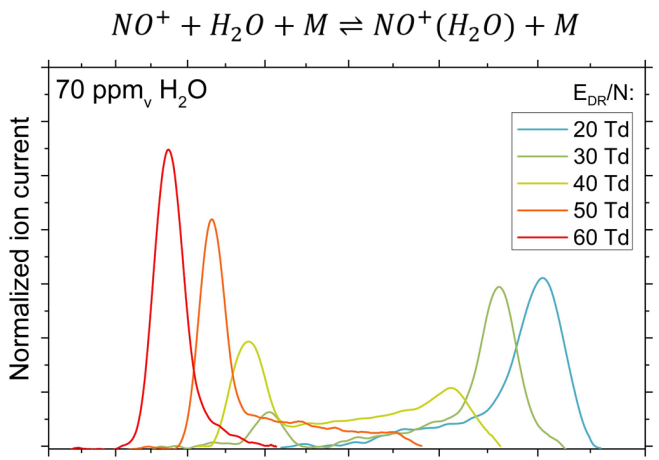

b)

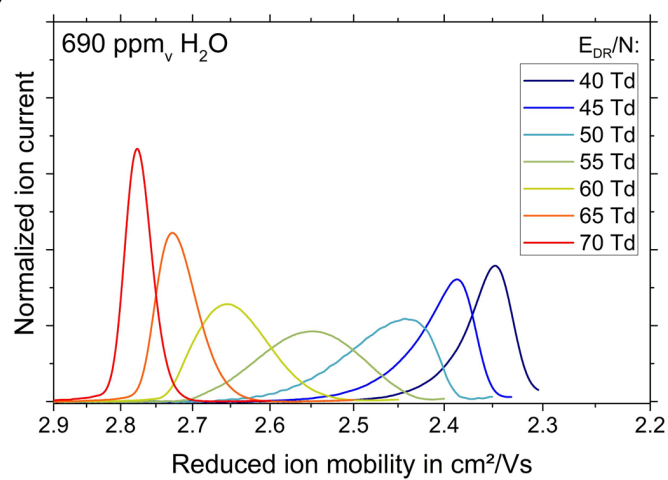

Figure 5: Recorded ion mobility spectra of $\mathrm{NO}^{+}\left(\mathrm{H}_{2} \mathrm{O}\right)_{n}$ in purified air at different reduced electric drift field strengths, the reduced reaction field strength is constant at $15 \mathrm{Td}$. a) Drift gas humidity of 70 ppm. b). Drift gas humidity of 690 ppm. The pressure is $14.3 \mathrm{mbar}$, the temperature is $45^{\circ} \mathrm{C}$. All spectra are normalized to the total charge in the spectrum.

In Figure 6 and in the supporting information, the measured reduced ion mobilities of $\mathrm{NO}^{+}\left(\mathrm{H}_{2} \mathrm{O}\right)_{n}$ in purified air and nitrogen are summarized in dependence on the reduced electric drift field strength for three different drift gas humidities. Due to the residual amount of neutral oxygen, small amounts of $\mathrm{NO}^{+}\left(\mathrm{H}_{2} \mathrm{O}\right)_{n}$ are generated even in nitrogen ${ }^{27}$. As known from $\mathrm{H}_{3} \mathrm{O}^{+}\left(\mathrm{H}_{2} \mathrm{O}\right)_{n}$, the reduced ion mobilities in air are higher than in nitrogen and the cluster transitions can be recognized by an increased slope of the reduced ion mobility curve. It is noted that the mobility data are not available for all reduced electric field strengths caused by overlapping peaks or low peak intensities.
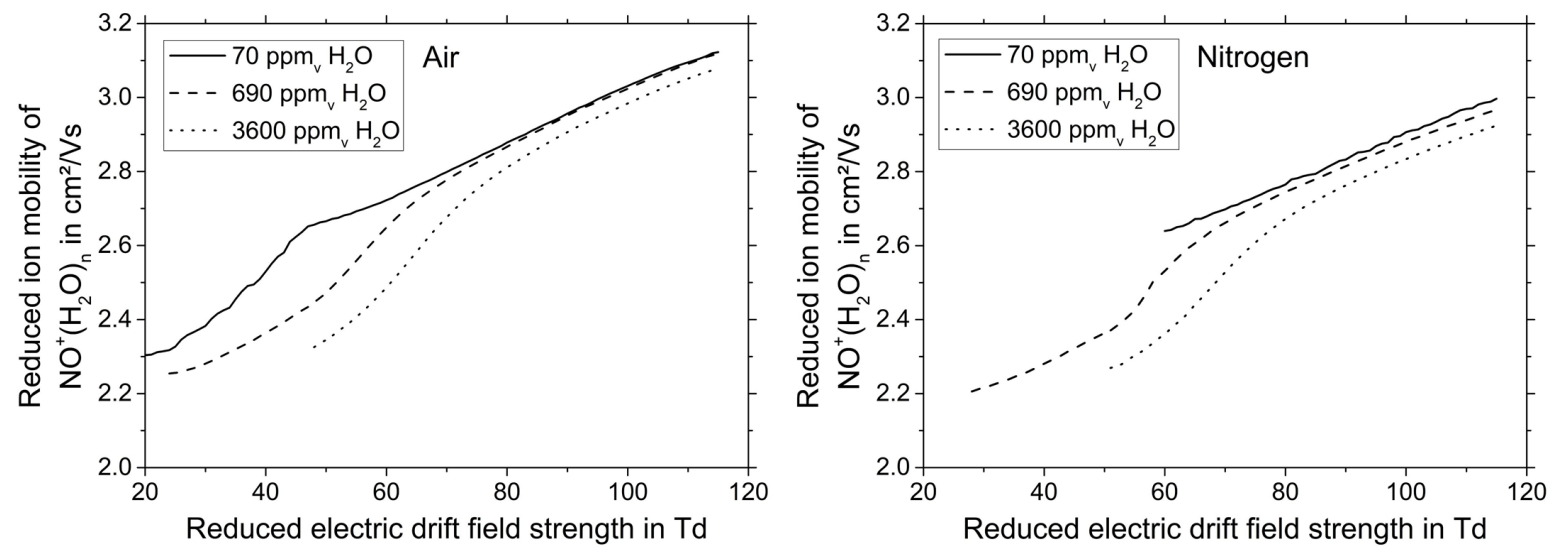

Figure 6: Recorded reduced ion mobilities of $\mathrm{NO}^{+}\left(\mathrm{H}_{2} \mathrm{O}\right)_{n}$ in purified air (left) and nitrogen (right) in dependence on the reduced electric drift field strength for three different drift gas humidities. In the measurements, the reduced electric reaction field strength is $15 \mathrm{Td}$ at the drift gas humidity of $70 \mathrm{ppm}_{\mathrm{v}}$ and $115 \mathrm{Td}$ at the drift gas humidities $690 \mathrm{ppm}_{\mathrm{v}}$ and $3600 \mathrm{ppm}_{\mathrm{v}}$, the pressure is $14.3 \mathrm{mbar}$, the temperature is $45^{\circ} \mathrm{C}$. The stated reduced ion mobility is the weighted average reduced ion mobility of the $\mathrm{NO}^{+}\left(\mathrm{H}_{2} \mathrm{O}\right)_{n}$ peak. 


\section{$\underline{\mathrm{O}}_{2}^{+}\left(\mathrm{H}_{2} \underline{\mathrm{O}}\right)_{n}$}

Mobility data for $\mathrm{O}_{2}^{+}\left(\mathrm{H}_{2} \mathrm{O}\right)_{n}$ are only available for reduced electric drift field strengths exceeding $100 \mathrm{Td}$ and a background water concentration of $70 \mathrm{ppm}_{\mathrm{v}}$. Otherwise, the mobility measurements are affected by the conversion reaction of $\mathrm{O}_{2}^{+}\left(\mathrm{H}_{2} \mathrm{O}\right)_{n}$ to $\mathrm{H}_{3} \mathrm{O}^{+}\left(\mathrm{H}_{2} \mathrm{O}\right)_{n}$ inside the drift region.

The measured reduced ion mobilities of $\mathrm{O}_{2}{ }^{+}\left(\mathrm{H}_{2} \mathrm{O}\right)_{n}$ in purified air and nitrogen in dependence on the reduced electric drift field strength are shown in Figure $7 \mathrm{a}$ and in the supporting information. Due to residual amounts of neutral oxygen, small amounts of $\mathrm{O}_{2}{ }^{+}\left(\mathrm{H}_{2} \mathrm{O}\right)_{n}$ are generated even in nitrogen ${ }^{27}$. In contrast to $\mathrm{H}_{3} \mathrm{O}^{+}\left(\mathrm{H}_{2} \mathrm{O}\right)_{n}$ and $\mathrm{NO}^{+}\left(\mathrm{H}_{2} \mathrm{O}\right)_{n}$, the reduced ion mobility of $\mathrm{O}_{2}{ }^{+}\left(\mathrm{H}_{2} \mathrm{O}\right)_{n}$ is lower in air than in nitrogen. Furthermore, in air, the reduced ion mobility of $\mathrm{O}_{2}{ }^{+}\left(\mathrm{H}_{2} \mathrm{O}\right)_{n}$ is nearly independent of the reduced drift field strength while in nitrogen, the reduced ion mobility of $\mathrm{O}_{2}^{+}\left(\mathrm{H}_{2} \mathrm{O}\right)_{n}$ increases with increasing reduced drift field strength. Both effects could be explained by a resonant transfer of charge. This phenomenon is observed for ions drifting in a gas containing their neutral precursors or molecules of similar electronic structure. Here, the transfer of an electron from an ion to a neutral proceeds easily and leads to an enhancement of the effective ion neutral collision cross section and thus to a reduction of the ion mobility ${ }^{53,54,5}$. Hence, due to the abundance of neutral oxygen in air, the reduced ion mobility of $\mathrm{O}_{2}{ }^{+}\left(\mathrm{H}_{2} \mathrm{O}\right)_{n}$ is lower in air than in nitrogen.

The effect of resonant charge transfer is additionally illustrated in the experiment shown in Figure $7 \mathrm{~b}$ and Figure $7 \mathrm{c}$. In this experiment, the fraction of neutral $\mathrm{O}_{2}$ in the drift gas is varied between $0 \%$ and $20 \%$ by mixing pure nitrogen with air containing approx. $80 \%$ nitrogen and $20 \%$ oxygen. According to Blanc's law ${ }^{55,56}$, the results show an increase of the reduced ion mobilities of $\mathrm{NO}^{+}\left(\mathrm{H}_{2} \mathrm{O}\right)_{n}$ and $\mathrm{H}_{3} \mathrm{O}^{+}\left(\mathrm{H}_{2} \mathrm{O}\right)_{n}$ when increasing the fraction of $\mathrm{O}_{2}$ in the drift gas. In contrast, due to the effect of resonant charge transfer, the reduced ion mobility of $\mathrm{O}_{2}^{+}\left(\mathrm{H}_{2} \mathrm{O}\right)_{n}$ decreases strongly when the fraction of $\mathrm{O}_{2}$ in the drift gas is increased. Due to overlapping peaks, mobility data are not available for all $\mathrm{O}_{2}$ frictions.
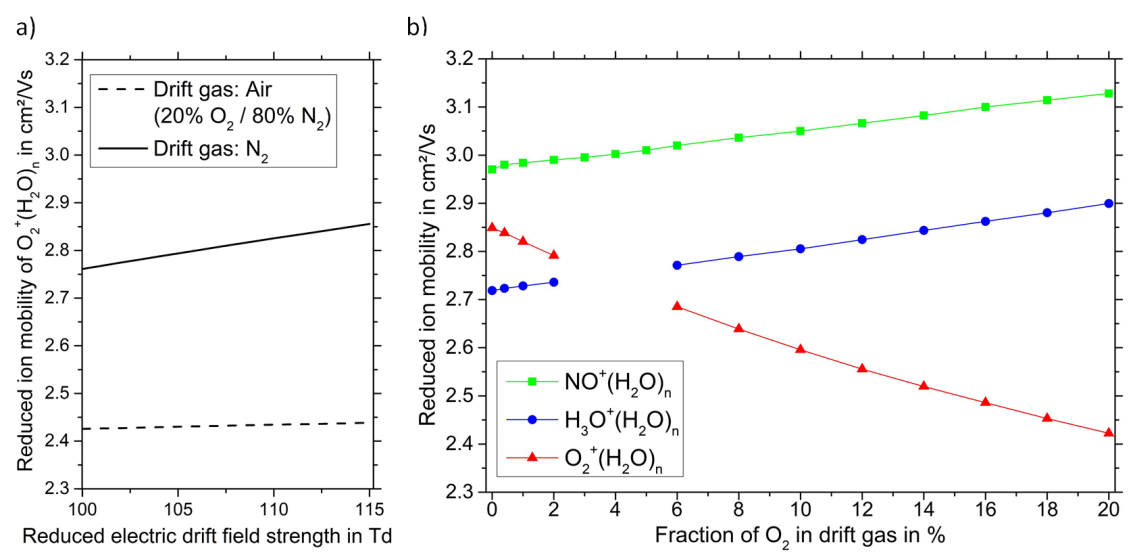

c)

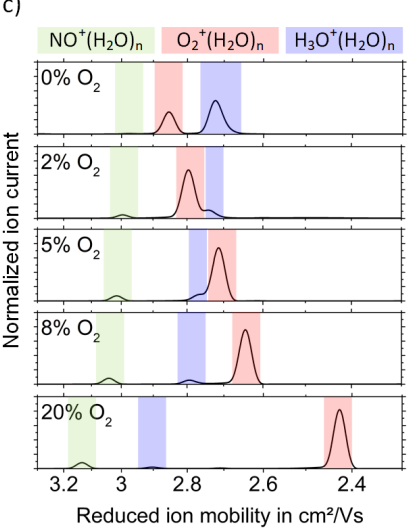

Figure 7: a) Recorded reduced ion mobilities of $\mathrm{O}_{2}^{+}\left(\mathrm{H}_{2} \mathrm{O}\right)_{n}$ in purified air and nitrogen in dependence on the reduced electric drift field strength at a background water concentration of $70 \mathrm{ppm}_{\mathrm{v}}$. b) Recorded reduced ion mobilities of $\mathrm{NO}^{+}\left(\mathrm{H}_{2} \mathrm{O}\right)_{n}$, $\mathrm{H}_{3} \mathrm{O}^{+}\left(\mathrm{H}_{2} \mathrm{O}\right)_{n}$ and $\mathrm{O}_{2}^{+}\left(\mathrm{H}_{2} \mathrm{O}\right)_{n}$ at different mixing ratios of nitrogen to air in the drift gas. c) Corresponding ion mobility spectra at different mixing ratios. In all measurements, the reduced electric reaction field strength is $115 \mathrm{Td}$, the pressure is $14.3 \mathrm{mbar}$ and the temperature is $45^{\circ} \mathrm{C}$. All spectra are normalized to the total charge in the spectrum.

\section{Other ion bound water cluster systems}

In addition to the investigation of the reduced ion mobilities of $\mathrm{H}_{3} \mathrm{O}^{+}\left(\mathrm{H}_{2} \mathrm{O}\right)_{n}, \mathrm{NO}^{+}\left(\mathrm{H}_{2} \mathrm{O}\right)_{n}$, and $\mathrm{O}_{2}{ }^{+}\left(\mathrm{H}_{2} \mathrm{O}\right)_{n}$, the reduced ion mobilities of $\mathrm{NO}_{2}^{+}\left(\mathrm{H}_{2} \mathrm{O}\right)_{n}, \mathrm{NH}_{4}^{+}\left(\mathrm{H}_{2} \mathrm{O}\right)_{n}, \mathrm{O}_{2}^{-}\left(\mathrm{H}_{2} \mathrm{O}\right)_{n}, \mathrm{O}_{3}^{-}\left(\mathrm{H}_{2} \mathrm{O}\right)_{n}, \mathrm{CO}_{3}^{-}\left(\mathrm{H}_{2} \mathrm{O}\right)_{n}, \mathrm{HCO}_{3}^{-}\left(\mathrm{H}_{2} \mathrm{O}\right)_{n}$, and $\mathrm{NO}_{2}^{-}\left(\mathrm{H}_{2} \mathrm{O}\right)_{\mathrm{n}}$ were also investigated. In the supporting information, the measured reduced ion mobilities are summarized in dependence on the reduced electric drift field strength and the effective ion temperatures calculated according to the Wannier equation. Due to overlapping peaks or low peak intensities, the data are not available for all reduced electric field strengths and effective ion 
temperatures, respectively. It is noted that the values are reported to the thousandth digit although the relative error regarding the reduced ion mobility has been estimated to be $0.64 \%$ resulting in an absolute error of at least $\pm 0.012 \mathrm{~cm}^{2} /$ Vs. Hence, only the hundredth digit should be significant. However, the thousandths digit is required to give a better sense of the trends going on. As the sources of error are the same for all values, the presented trends should be valid.

\section{Conclusion}

In this work, a HiKE-IMS is used to study the dependence of the reduced ion mobilities of several hydrated ion species in air and nitrogen on the drift gas humidity and the effective ion temperature. Due to the operation at decreased pressure and high reduced electric field strengths, experiments with the HiKE-IMS allow insights into the chemical kinetics of ion bound water cluster systems at effective ion temperatures exceeding $1000 \mathrm{~K}$. Furthermore, the high mobility resolving power of 140 enables the direct observation of cluster transitions in the ion mobility spectrum upon varying the reduced electric field strength in the drift region. This has been demonstrated for the proton bound water cluster system $\mathrm{H}_{3} \mathrm{O}^{+}\left(\mathrm{H}_{2} \mathrm{O}\right)_{n}$ and the nitrogen oxide ion bound water cluster system $\mathrm{NO}^{+}\left(\mathrm{H}_{2} \mathrm{O}\right)_{n}$. Increasing the reduced electric drift field strength beyond a threshold value, the peak of these systems becomes skewed due to a rapid change in the reduced ion mobility. In this work, comprehensive measurements have been performed to determine the reduced ion mobilities of the positive reactant ions $\mathrm{H}_{3} \mathrm{O}^{+}\left(\mathrm{H}_{2} \mathrm{O}\right)_{n}, \mathrm{O}_{2}{ }^{+}\left(\mathrm{H}_{2} \mathrm{O}\right)_{n}, \mathrm{NO}^{+}\left(\mathrm{H}_{2} \mathrm{O}\right)_{n}, \mathrm{NO}_{2}{ }^{+}\left(\mathrm{H}_{2} \mathrm{O}\right)_{n}$, and $\mathrm{NH}_{4}{ }^{+}\left(\mathrm{H}_{2} \mathrm{O}\right)_{n}$, as well as the negative reactant ions $\mathrm{O}_{2}^{-}\left(\mathrm{H}_{2} \mathrm{O}\right)_{n}, \mathrm{O}_{3}^{-}\left(\mathrm{H}_{2} \mathrm{O}\right)_{n}, \mathrm{CO}_{3}^{-}\left(\mathrm{H}_{2} \mathrm{O}\right)_{n}, \mathrm{HCO}_{3}^{-}\left(\mathrm{H}_{2} \mathrm{O}\right)_{n}$, and $\left.\mathrm{NO}_{2}-\mathrm{H}_{2} \mathrm{O}\right)_{n}$ in dependence on the effective ion temperature at three different drift gas humidities in purified air and nitrogen. The reported data are regarded as relevant in a number of methods and applications such as DMS, PTR-MS or SIFDT-MS.

\section{Acknowledgment}

This work was funded by the Deutsche Forschungsgemeinschaft (DFG, German Research Foundation), joint project BE 2124/8-1 - ZI 1288/8-1

\section{Supporting information}

Table S1: Recorded reduced ion mobilities of the positive ions $\mathrm{H}_{3} \mathrm{O}^{+}\left(\mathrm{H}_{2} \mathrm{O}\right)_{n}, \mathrm{NO}^{+}\left(\mathrm{H}_{2} \mathrm{O}\right)_{n}, \mathrm{O}_{2}{ }^{+}\left(\mathrm{H}_{2} \mathrm{O}\right)_{n}$ and $\mathrm{NO}_{2}^{+}\left(\mathrm{H}_{2} \mathrm{O}\right)_{n}$ in air as a function of the reduced electric drift field strength and the effective ion temperature calculated according to the Wannier equation for three different background water concentrations. Absolute temperature $=45^{\circ} \mathrm{C}$, operating pressure $=14.3 \mathrm{mbar}$.

Table S2: Recorded reduced ion mobilities of the positive ions $\mathrm{H}_{3} \mathrm{O}^{+}\left(\mathrm{H}_{2} \mathrm{O}\right)_{n}, \mathrm{NO}^{+}\left(\mathrm{H}_{2} \mathrm{O}\right)_{n}, \mathrm{O}_{2}{ }^{+}\left(\mathrm{H}_{2} \mathrm{O}\right)_{n}$ and $\mathrm{NH}_{4}^{+}\left(\mathrm{H}_{2} \mathrm{O}\right)_{n}$ in nitrogen as a function of the reduced electric drift field strength and the effective ion temperature calculated according to the Wannier equation for three different background water concentrations. Absolute temperature $=45^{\circ} \mathrm{C}$, operating pressure $=14.3 \mathrm{mbar}$.

Table S3: Recorded reduced ion mobilities of the negative ions $\mathrm{O}_{2}^{-}\left(\mathrm{H}_{2} \mathrm{O}\right)_{n}, \mathrm{O}_{3}^{-}\left(\mathrm{H}_{2} \mathrm{O}\right)_{n}, \mathrm{CO}_{3}^{-}\left(\mathrm{H}_{2} \mathrm{O}\right)_{n}$, $\mathrm{HCO}_{3}^{-}\left(\mathrm{H}_{2} \mathrm{O}\right)_{\mathrm{n}}$ and $\mathrm{NO}_{2}^{-}\left(\mathrm{H}_{2} \mathrm{O}\right)_{n}$ in air as a function of the reduced electric drift field strength and the effective ion temperature calculated according to the Wannier equation for three different background water concentrations. Absolute temperature $=45^{\circ} \mathrm{C}$, operating pressure $=14.3 \mathrm{mbar}$. 


\section{References}

(1) Eiceman, G. A.; Karpas, Z.; Hill, H. H. Ion mobility spectrometry, 3rd edn.; CRC Press: Boca Ration, Fla., 2014.

(2) Borsdorf, H.; Mayer, T.; Zarejousheghani, M.; Eiceman, G. A. Recent Developments in lon Mobility Spectrometry. Appl. Spectrosc. Rev. 2011, 46, 472-521.

(3) Kirk, A. T.; Bohnhorst, A.; Raddatz, C.-R.; Allers, M.; Zimmermann, S. Ultra-high-resolution ion mobility spectrometry-current instrumentation, limitations, and future developments. Anal. Bioanal. Chem. 2019, 411, 6229-6246.

(4) Mason, E. A.; McDaniel, E. W. Transport properties of ions in gases; Wiley: New York, 1988.

(5) Viehland, L. A. Gaseous Ion Mobility, Diffusion, and Reaction; Springer International Publishing: Cham, 2018.

(6) Mayer, T.; Borsdorf, H. Accuracy of ion mobility measurements dependent on the influence of humidity. Anal. Chem. 2014, 86, 5069-5076.

(7) Hauck, B. C.; Davis, E. J.; Clark, A. E.; Siems, W. F.; Harden, C. S.; McHugh, V. M.; Hill, H. H. Determining the water content of a drift gas using reduced ion mobility measurements. Int. J. Mass Spectrom. 2014, 368, 37-44.

(8) Wannier, G. H. Motion of Gaseous Ions in Strong Electric Fields. Bell System Technical Journal 1953, 32, 170-254.

(9) Yousef, A.; Shrestha, S.; Viehland, L. A.; Lee, E. P. F.; Gray, B. R.; Ayles, V. L.; Wright, T. G.; Breckenridge, W. H. Interaction potentials and transport properties of coinage metal cations in rare gases. J. Chem. Phys. 2007, 127, 154309.

(10) Eiceman, G. A.; Nazarov, E. G.; Rodriguez, J. E.; Bergloff, J. F. Positive Reactant lon Chemistry for Analytical, High Temperature Ion Mobility Spectrometry (IMS): Effects of Electric Field of the Drift Tube and Moisture, Temperature, and Flow of the Drift Gas. Int. J. Ion Mobil. Spectrom. 1998, 1, $28-$ 37.

(11) Tabrizchi, M. Temperature Corrections for Ion Mobility Spectrometry. Appl. Spectrosc. 2001, 55, 1653-1659.

(12) Tabrizchi, M.; Rouholahnejad, F. Comparing the effect of pressure and temperature on ion mobilities. Anal. Chem. 2005, 38, 857-862.

(13) Fernandez-Maestre, R.; Meza-Morelos, D.; Wu, C. Mobility shifts when buffer gas temperature increases in ion mobility spectrometry are affected by intramolecular bonds. Int. J. Mass Spectrom. 2016, 407, 113-117.

(14) Borsdorf, H.; Mayer, T. Temperature dependence of ion mobility signals of halogenated compounds. Talanta 2012, 101, 17-23.

(15) Zhang, B.; He, J.; Ji, Y. Dependence of the average mobility of ions in air with pressure and humidity. IEEE Trans. Dielect. Electr. Insul. 2017, 24, 923-929.

(16) Mäkinen, M.; Sillanpää, M. E. T.; Viitanen, A.-K.; Knap, A.; Mäkelä, J. M.; Puton, J. The effect of humidity on sensitivity of amine detection in ion mobility spectrometry. Talanta 2011, 84, 116-121. (17) Izadi, Z.; Tabrizchi, M.; Borsdorf, H.; Farrokhpour, H. Humidity Effect on the Drift Times of the Reactant lons in Ion Mobility Spectrometry. Anal. Chem. 2019, 91, 15932-15940.

(18) Langejuergen, J.; Allers, M.; Oermann, J.; Kirk, A. T.; Zimmermann, S. High kinetic energy ion mobility spectrometer: quantitative analysis of gas mixtures with ion mobility spectrometry. Anal. Chem. 2014, 86, 7023-7032.

(19) Langejuergen, J.; Allers, M.; Oermann, J.; Kirk, A. T.; Zimmermann, S. Quantitative detection of benzene in toluene- and xylene-rich atmospheres using high-kinetic-energy ion mobility spectrometry (IMS). Anal. Chem. 2014, 86, 11841-11846. 
(20) Kirk, A. T.; Grube, D.; Kobelt, T.; Wendt, C.; Zimmermann, S. High-Resolution High Kinetic Energy Ion Mobility Spectrometer Based on a Low-Discrimination Tristate Ion Shutter. Anal. Chem. 2018, 90, 5603-5611.

(21) Shvartsburg, A. A. Differential ion mobility spectrometry; CRC Press: Boca Raton, 2009.

(22) Ellis, A. M.; Mayhew, C. A. Proton Transfer Reaction Mass Spectrometry; John Wiley \& Sons, Ltd: Chichester, UK, 2014.

(23) Smith, D.; Ŝpaněl, P. SIFT-MS and FA-MS methods for ambient gas phase analysis: developments and applications in the UK. Analyst 2015, 140, 2573-2591.

(24) Spesyvyi, A.; Smith, D.; Ŝpaněl, P. Selected Ion Flow-Drift Tube Mass Spectrometry:

Quantification of Volatile Compounds in Air and Breath. Anal. Chem. 2015, 87, 12151-12160.

(25) Allers, M.; Kirk, A. T.; Eckermann, M.; Schaefer, C.; Erdogdu, D.; Wissdorf, W.; Benter, T.;

Zimmermann, S. Positive Reactant Ion Formation in High Kinetic Energy lon Mobility Spectrometry

(HiKE-IMS). J. Am. Soc. Mass Spectrom. 2020, 31, 1291-1301.

(26) Allers, M.; Kirk, A. T.; Timke, B.; Erdogdu, D.; Wissdorf, W.; Benter, T.; Zimmermann, S. Negative Reactant Ion Formation in High Kinetic Energy Ion Mobility Spectrometry (HiKE-IMS). J. Am. Soc. Mass Spectrom. 2020, Just accepted.

(27) Allers, M.; Kirk, A. T.; Roßbitzky, N. von; Erdogdu, D.; Hillen, R.; Wissdorf, W.; Benter, T.; Zimmermann, S. Analyzing Positive Reactant Ions in High Kinetic Energy lon Mobility Spectrometry (HiKE-IMS) by HiKE-IMS-MS. J. Am. Soc. Mass Spectrom. 2020, 31, 812-821.

(28) Crawford, C. L.; Hauck, B. C.; Tufariello, J. A.; Harden, C. S.; McHugh, V.; Siems, W. F.; Hill, H. H. Accurate and reproducible ion mobility measurements for chemical standard evaluation. Talanta 2012, 101, 161-170.

(29) Hauck, B. C.; Siems, W. F.; Harden, C. S.; McHugh, V. M.; Hill, H. H. E/N effects on KO values revealed by high precision measurements under low field conditions. Rev. Sci. Instrum. 2016, 87, 75104.

(30) Hauck, B. C.; Siems, W. F.; Harden, C. S.; McHugh, V. M.; Hill, H. H. Construction and evaluation of a hermetically sealed accurate ion mobility instrument. Int. J. Ion Mobil. Spectrom. 2017, 20, 5766.

(31) Kirk, A. T.; Bakes, K.; Zimmermann, S. A universal relationship between optimum drift voltage and resolving power. Int. J. Ion Mobil. Spectrom. 2017, 20, 105-109.

(32) Kirk, A. T.; Zimmermann, S. Bradbury-Nielsen vs. Field switching shutters for high resolution drift tube ion mobility spectrometers. Int. J. Ion Mobil. Spectrom. 2014, 17, 131-137.

(33) Working Group 1 of the Joint Committee for Guides in Metrology. Evaluation of measurement data - Guide to the expression of uncertainty in measurement.

(34) Wissdorf, W.; Seifert, L.; Derpmann, V.; Klee, S.; Vautz, W.; Benter, T. Monte Carlo simulation of ion trajectories of reacting chemical systems: mobility of small water clusters in ion mobility spectrometry. J. Am. Soc. Mass Spectrom. 2013, 24, 632-641.

(35) Good, A.; Durden, D. A.; Kebarle, P. Ion-Molecule Reactions in Pure Nitrogen and Nitrogen Containing Traces of Water at Total Pressures 0.5-4 torr. Kinetics of Clustering Reactions Forming $\mathrm{H}+$ (H 2 O) n. J. Chem. Phys. 1970, 52, 212-221.

(36) Howard, C. J.; Rundle, H. W.; Kaufman, F. Water Cluster Formation Rates of NO + in He, Ar, N 2, and $\mathrm{O} 2$ at $296^{\circ}$ K. J. Chem. Phys. 1971, 55, 4772-4776.

(37) Raksit, A. B.; Warneck, P. A drift chamber study of the formation of water cluster ions in oxygen. J. Chem. Phys. 1980, 73, 5074-5080.

(38) Fehsenfeld, F. C.; Ferguson, E. E. Laboratory studies of negative ion reactions with atmospheric trace constituents. J. Chem. Phys. 1974, 61, 3181-3193.

(39) Lau, Y. K.; Ikuta, S.; Kebarle, P. Thermodynamics and kinetics of the gas-phase reactions $\mathrm{H} 3 \mathrm{O}+(\mathrm{H} 2 \mathrm{O}) \mathrm{n}-1+$ water $=\mathrm{H} 3 \mathrm{O}+(\mathrm{H} 2 \mathrm{O})$ n. J. Am. Chem. Soc. 1982, 104, 1462-1469. 
(40) Payzant, J. D.; Cunningham, A. J.; Kebarle, P. Gas Phase Solvation of the Ammonium Ion by NH3 and $\mathrm{H} 2 \mathrm{O}$ and Stabilities of Mixed Clusters NH4+(NH3)n(H2O)w. Can. J. Chem. 1973, 51, 3242-3249.

(41) French, M. A.; Hills, L. P.; Kebarle, P. Kinetics and Temperature Dependence of the Hydration of $\mathrm{NO}+$ in the Gas Phase. Can. J. Chem. 1973, 51, 456-461.

(42) Binning, R. C.; Ishikawa, Y. Structures of NO $2+(\mathrm{H} 2 \mathrm{O}) \mathrm{n}$ and (HNO 3$)(\mathrm{H} 3 \mathrm{O}+)(\mathrm{H} 2 \mathrm{O}) \mathrm{n}-2(\mathrm{n}=$ 2-4) Clusters. J. Phys. Chem. A 2000, 104, 8097-8104.

(43) Sharma, S.; Wright, T. G.; Besley, N. A. Reactivity of the O2+·( $\mathrm{H} 2 \mathrm{O}) \mathrm{n}$ and NO+·(H2O)n cluster ions in the D-region of the ionosphere. Phys. Chem. Chem. Phys. 2018, 20, 25931-25938.

(44) Arshadi, M.; Kebarle, P. Hydration of $\mathrm{OH}$ - and O2- in the gas phase. Comparative solvation of $\mathrm{OH}$ by water and the hydrogen halides. Effects of acidity. J. Phys. Chem. 1970, 74, 1483-1485.

(45) Keesee, R. G.; Lee, N.; Castleman, A. W. Properties of clusters in the gas phase. 3. Hydration complexes of carbonate(1-) and bicarbonate(1-) ions. J. Am. Chem. Soc. 1979, 101, 2599-2604.

(46) Payzant, J. D.; Yamdagni, R.; Kebarle, P. Hydration of CN -, NO 2-, NO 3-, and $\mathrm{OH}$ - in the Gas Phase. Can. J. Chem. 1971, 49, 3308-3314.

(47) Gouw, J. de; Warneke, C.; Karl, T.; Eerdekens, G.; van der Veen, C.; Fall, R. Sensitivity and specificity of atmospheric trace gas detection by proton-transfer-reaction mass spectrometry. Int. J. Mass Spectrom. 2003, 223-224, 365-382.

(48) Brown, P.; Watts, P.; Märk, T. D.; Mayhew, C. A. Proton transfer reaction mass spectrometry investigations on the effects of reduced electric field and reagent ion internal energy on product ion branching ratios for a series of saturated alcohols. Int. J. Mass Spectrom. 2010, 294, 103-111.

(49) Kambara, H.; Kanomata, I. Collision-induced dissociation of water cluster ions at high pressure. Int. J. Mass Spectrom. Ion Phys. 1977, 25, 129-136.

(50) Kirk, A. T.; Raddatz, C.-R.; Zimmermann, S. Separation of Isotopologues in Ultra-High-Resolution Ion Mobility Spectrometry. Anal. Chem. 2017, 89, 1509-1515.

(51) Viehland, L. A.; Mason, E. A. Transport Properties of Gaseous Ions over a Wide Energy Range, IV. At. Data Nucl. Data Tables 1995, 60, 37-95.

(52) Matz, L. M.; Hill, H. H.; Beegle, L. W.; Kanik, I. Investigation of drift gas selectivity in high resolution ion mobility spectrometry with mass spectrometry detection. J. Am. Soc. Mass Spectrom. 2002, 13, 300-307.

(53) Cumeras, R.; Figueras, E.; Davis, C. E.; Baumbach, J. I.; Gràcia, I. Review on ion mobility spectrometry. Part 2: hyphenated methods and effects of experimental parameters. Analyst 2015, 140, 1391-1410.

(54) Nazarov, E. G.; Coy, S. L.; Krylov, E. V.; Miller, R. A.; Eiceman, G. A. Pressure effects in differential mobility spectrometry. Anal. Chem. 2006, 78, 7697-7706.

(55) Blanc, A. Recherches sur les mobilités des ions dans les gaz. J. Phys. Theor. Appl. 1908, 7, 825839.

(56) Naylor, C. N.; Reinecke, T.; Clowers, B. H. Assessing the Impact of Drift Gas Polarizability in Polyatomic Ion Mobility Experiments. Anal. Chem. 2020, 92, 4226-4234. 